\title{
Relation between severity of mitral valve disease and results of routine lung function tests in non-smokers
}

\author{
KM RHODES, ${ }^{*}$ K EVEMY, S NARIMAN, GJ GIBSON \\ From the Cardiothoracic Centre, Freeman Hospital, Newcastle upon Tyne
}

ABSTRACT The effects of mitral valve disease on lung function have been studied in 26 nonsmoking patients by relating values for lung volumes and carbon monoxide transfer factor (TLCO) to various indices of cardiac function measured at catheterisation. In general, more severe mitral disease was associated with greater abnormalities of lung function. Reductions of the one-second forced expiratory volume, vital capacity, TLCO and transfer coefficient, and increase in residual volume were all significantly related to the severity of mitral valve disease. In addition, the cardiothoracic ratio, measured radiographically, showed an inverse correlation with both vital capacity and total lung capacity. Although some of the consequences of mitral valve disease on lung function resemble those of primary airway disease, useful distinguishing points are the relative normality of the forced expiratory ratio and the absence of an increase in total lung capacity.

Abnormalities of lung mechanics and gas transfer are well recognised in initral valve disease but interpretation of the results of routine lung function tests in an individual patient is often difficult since the findings are not specific. The degree of abnormality in the results of simple tests that can result from mitral disease alone remains unclear, and most studies have taken no account of cigarette smoking. Attempts to correlate the severity of the valve disease with quantitative changes in lung function have produced variable results. Although relationships have been shown ${ }^{12}$ between lung function and severity of dyspnoea, this does not necessarily give information about the cardiac contribution since both could reflect airways obstruction due to smoking. The only way to quantitate the effects of mitral disease per se would be to exclude patients with primary respiratory disease; but since chronic cough, sputum, and wheezing are often attributed to mitral disease patients cannot be excluded on symptomatic grounds alone. We have therefore identified a group of patients with mitral disease who have no history of previous respiratory disease and who are effectively nonsmokers, firstly, to assess the quantitative effects of mitral disease alone on the results of routine tests of lung function and, secondly, to examine the correlations between various indices of mitral valve function

*Present address: Western Hospital, Southampton.

Address for correspondence (no reprints): Dr GJ Gibson, Freeman Hospital, High Heaton, Newcastle upon Tyne NE7 7DN. and lung volumes, carbon monoxide transfer factor (TLCO), and transfer coefficient (KCO).

\section{Methods}

Of a total of 72 consecutive patients with mitral valve disease undergoing cardiac catheterisation in the regional cardiothoracic centre, 26 were effectively nonsmokers and their results are described here (three of the 26 were ex-smokers but had smoked less than a total of five pack-years). Their ages ranged from 23 to 63 . The patients comprised 20 with dominant mitral stenosis (nine of whom also had significant mitral regurgitation) and six with dominant mitral regurgitation (three of whom also had some stenosis), classified by the findings at cardiac catheterisation. Three patients had significant aortic regurgitation in addition to the mitral lesions. No patient had heart failure on clinical criteria at the time of study but one showed septal lines on the chest radiograph. None had evidence of primary lung disease as assessed from the history and chest radiograph.

Respiratory symptoms were recorded. All except one had dyspnoea less than grade 3 (short of breath while walking at own pace on the flat). Heart size was estimated from the cardiothoracic ratio on a standard posteroanterior chest radiograph.

All patients underwent left and right cardiac catheterisation as part of their clinical investigation. The severity of mitral valve disease was assessed from 
the pulmonary artery pressure, the mean pulmonary wedge pressure (with reference to the mid-axillary line), and the diastolic pressure gradient across the mitral valve (wedge pressure minus simultaneous left ventricular pressure). The latter was measured at a standard time, $750 \mathrm{~ms}$ after the $\mathrm{R}$ wave of the preceding ventricular complex, and the mean value for three to five cardiac cycles was taken. The degree of mitral regurgitation was assessed by cineangiography. In 23 patients measurements of pulmonary artery and left ventricular blood oxygen saturation with prediction of the oxygen consumption ${ }^{3}$ allowed estimation of the cardiac output, expressed here after correction for body size as the cardiac index $\left(1 / \mathrm{min} / \mathrm{m}^{2}\right)$. In these patients the pulmonary arteriolar resistance was also calculated as (mean pulmonary artery pressure mean wedge pressure) $\div$ cardiac index. In 19 of the 20 patients with dominant mitral stenosis the "effective" valve area was calculated from the formula of Gorlin. ${ }^{4}$

Lung function tests were performed within two days of cardiac catheterisation. Forced expiratory volume in one second (FEV $)$ and vital capacity (VC) were measured with a bellows spirometer (Vitalograph) and total lung capacity and residual volume (in 24 patients) with a constant-volume whole-body plethysmograph $^{5}$ (PK Morgan). Carbon dioxide transfer factor (TLCo) was measured (in 25 patients) by the single-breath technique, ${ }^{6}$ on the basis of simultaneously estimated alveolar volume $\left(V_{A}\right)$, and the transfer coefficient (Kco) was calculated by dividing the transfer factor by VA. All lung function measurements were recorded as percentages of predicted values. $^{7}$

Individual regressions and multiple stepwise correlations were performed between the various indices of lung function and mitral valve disease.

\section{Results}

Of the 26 patients, two had a chronic productive cough that fulfilled the Medical Research Council criteria for chronic bronchitis and both were life-long non-smokers. Eleven patients $(42 \%)$ admitted to wheezing episodes. Although the patients who wheezed had a slightly lower mean $\mathrm{FEV}_{1} / \mathrm{VC}$ ratio (88.6\% predicted), this was not significantly different from the value in patients who did not wheeze (mean $99.4 \%$ predicted).

Table 1 summarises the haemodynamic and lung function data; the mitral valve gradient was not measurable in any of the patients with pure mitral regurgitation, in one patient with no satisfactory wedge recording, or in three with a cardiac cycle of less than $750 \mathrm{~ms}$. On average, the $F E V_{1}$ and vital capacity were reduced proportionately, the $\mathrm{FEV}_{1} /$ VC ratio and total lung capacity were essentially normal, and the residual volume was appreciably increased. The mean TLco was clearly reduced, though the Kco was only slightly lower than normal.

Table 2 shows the individual correlations between the lung function and haemodynamic data. There were no significant correlations between total lung capacity and any of the indices of cardiac function. Both FEV 1 and VC showed significant correlations with cardiac index and valve area and an inverse correlation with pulmonary vascular resistance. The $F E V_{1}$ and $F E V_{1} / V C$ ratio showed an inverse correlation with the valve gradient. The residual volume correlated significantly with valve gradient and pulmonary artery and pulmonary wedge pressures.

TLco showed significant correlations with cardiac index and valve area and inverse correlations with wedge pressure and vascular resistance. Kco showed significant inverse correlations with the valve gradient and wedge pressure.

Since there were clear relationships both within the pulmonary function indices and within the haemodynamic variables, multiple stepwise regressions were also performed. For each of the indices of lung function these showed that, once the effect of the best correlated haemodynamic variable had been accounted for, there were no significant relationships with the remaining variables.

Table 1 Haemodynamic and lung function data on the patients studied

\begin{tabular}{|c|c|c|c|}
\hline & No of patients & Range & Mean and SD \\
\hline $\begin{array}{l}\text { Mitral valve gradient (at } 750 \mathrm{~ms})(\mathrm{mm} \mathrm{Hg}) \\
\text { Mean pulmonary wedge pressure }(\mathrm{mm} \mathrm{Hg}) \\
\text { Mean pulmonary artery pressure }(\mathrm{mm} \mathrm{Hg}) \\
\text { Cardiac index }\left(1 / \mathrm{min} / \mathrm{m}^{2}\right) \\
\text { Pulmonary arteriolar resistance }\left(\mathrm{mm} \mathrm{Hg} / 1 / \mathrm{min} / \mathrm{m}^{2}\right) \\
\text { Mitral valve area }\left(\mathrm{cm}^{2}\right) \\
\text { FEV }(\% \text { predicted) } \\
\text { Vital capacity }(\% \text { predicted) } \\
\text { FEV } / \text { vital capacity }(\% \text { predicted) } \\
\text { Total lung capacity (\% predicted) } \\
\text { Residual volume }(\% \text { predicted) } \\
\text { TLco (\% predicted) } \\
\text { Kco (\% predicted) }\end{array}$ & $\begin{array}{l}19 \\
25 \\
26 \\
23 \\
22 \\
19 \\
26 \\
26 \\
26 \\
24 \\
24 \\
25 \\
25\end{array}$ & $\begin{array}{c}2-17.5 \\
9-35 \\
14-52 \\
1 \cdot 24-5 \cdot 68 \\
0 \cdot 7-10 \cdot 0 \\
0 \cdot 46-3 \cdot 06 \\
39-145 \\
45-130 \\
60-129 \\
69-147 \\
100-236 \\
48-121 \\
71-127\end{array}$ & $\begin{array}{r}7.29 \pm 4.34 \\
18.3 \pm 6.6 \\
26.08 \pm 9.03 \\
2.34 \pm 0.92 \\
3.96 \pm 2.09 \\
1.18 \pm 0.67 \\
83.2 \pm 25.7 \\
86.7 \pm 20.4 \\
94.9 \pm 15.7 \\
107.5 \pm 18.5 \\
149.6 \pm 16.9 \\
74.4 \pm 17.1 \\
92.8 \pm 14.7\end{array}$ \\
\hline
\end{tabular}


Table 2 Correlation coefficients between regressions of lung function tests and haemodynamic data

\begin{tabular}{|c|c|c|c|c|c|c|}
\hline & Mitral valve gradient & $\begin{array}{l}\text { Mean wedge } \\
\text { pressure }\end{array}$ & $\begin{array}{l}\text { Mean pulmonary } \\
\text { artery pressure }\end{array}$ & $\begin{array}{l}\text { Cardiac } \\
\text { index }\end{array}$ & $\begin{array}{l}\text { Pulmonary } \\
\text { arteriolar } \\
\text { resistance }\end{array}$ & $\begin{array}{l}\text { Mitral } \\
\text { valve } \\
\text { area }\end{array}$ \\
\hline $\mathrm{FEV}_{\mathbf{1}}$ & $-0.55^{*}$ & -0.33 & -0.35 & $0.42^{*}$ & $-0.43^{*}$ & $0.56^{*}$ \\
\hline Vital capacity & $-0 \cdot 36$ & $-0 \cdot 32$ & -0.35 & $0.42^{*}$ & $-0.51^{*}$ & $0.53^{*}$ \\
\hline FEV $1 /$ vital capacity & $-0.50^{*}$ & -0.37 & -0.25 & $0 \cdot 33$ & -0.06 & 0.41 \\
\hline Residual volume & $0.48^{*}$ & $0.49^{*}$ & $0.44^{*}$ & -0.07 & $0 \cdot 31$ & $-0 \cdot 19$ \\
\hline TLco & -0.45 & $-0.44^{*}$ & -0.37 & $0.46^{*}$ & $-0.53^{* *}$ & $0.62^{* *}$ \\
\hline Kco & $-0.52^{*}$ & $-0.45^{*}$ & -0.38 & 0.20 & -0.36 & 0.34 \\
\hline
\end{tabular}

Significance levels: ${ }^{*} \mathrm{p}<0.05 ;{ }^{* *} \mathrm{p}<0.01$.

There were significant inverse correlations (fig) between cardiothoracic ratio and both total lung capacity $(\mathrm{r}=-0.50 ; \mathrm{p}<0.02)$ and vital capacity $(\mathrm{r}=$ $-0.69 ; \mathrm{p}<0.001)$.

\section{Discussion}

In general, these results confirm that in non-smoking patients with mitral valve disease the more severe the valve defect the more abnormal the pulmonary function. Reduction of spirometric volumes, increase of residual volume, and reduction of TLCo and Kco correlated with varying degrees of significance with the severity of mitral valve disease or its consequences on the cardiac output and pulmonary vascular pressures. Where correlations did not reach statistical significance (table 2) the trends were generally

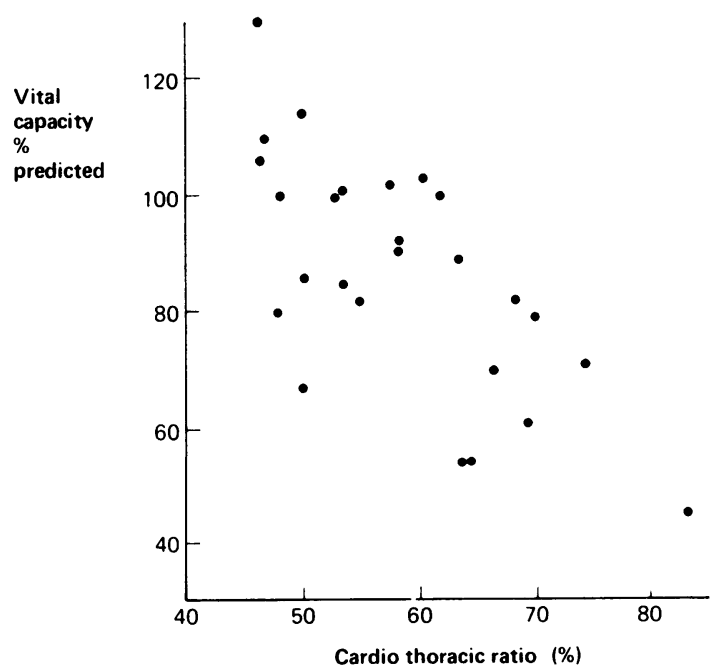

Relationship between vital capacity and cardiothoracic ratio in 26 non-smoking patients with mitral valve disease. consistent. Most of our patients were women but there is no reason to assume that the conclusions would not apply equally to men.

Previous studies have shown conflicting results when relating indices of lung function to those of cardiac disease but most have included smokers and some of the abnormalities of lung function could have been a consequence of cigarette-related disease rather than rheumatic heart disease alone. Some studies $^{128}$ have shown that those patients with the worst symptoms had the most abnormal lung function. Our study showed a similar trend but as most patients had a similar and moderate degree of dyspnoea we could not form any firm conclusions. Previous studies of the quantitative relationships between lung function and haemodynamic data are few and contradictory: negative correlations between vital capacity and pulmonary vascular resistance or mean pulmonary artery pressure have been reported ${ }^{910}$ but other studies ${ }^{1112}$ have found no relationships. We confirmed a significant relationship between vital capacity and pulmonary vascular resistance. The present study shows that both FEV 1 and vital capacity correlated best with the same indices of cardiac function - namely, pulmonary vascular resistance, cardiac output, and valve area. Since the $F E V_{1} / V C$ ratio was normal in most patients the correlations with FEV 1 largely follow from those with vital capacity. There was, however, a weak negative correlation of the ratio with the gradient across the mitral valve. On simple spirometric criteria therefore airflow obstruction was rarely a major feature in non-smoking patients with mitral valve disease, and this agrees with the findings in some other studies. ${ }^{210}$ Palmer $e t$ $a l^{1}$ suggested that airways obstruction may play an important part, but their study included smokers. We did not study patients with severe breathlessness and airways obstruction might be more prominent in the later stages. Eleven patients admitted to wheezing episodes; although the non-wheezers had a higher 
mean $\mathrm{FEV}_{1} / \mathrm{VC}$ ratio the difference was not statistically significant. The highly significant inverse relationship between cardiothoracic ratio and vital capacity suggests that some of the fall in vital capacity may be directly due to increased heart size in addition to the effects of vascular congestion.

The mean value of total lung capacity in our patients was normal ( $107 \%$ predicted), which agrees with other studies, and it showed no correlation with the severity of the valve disease. An increase in residual volume in mitral disease has been observed in many studies ${ }^{21013}$ and attributed to a reduction in lung recoil at small lung volumes. ${ }^{14}$ The present study confirmed that the increase in residual volume is correlated with the severity of the valve disease as assessed by the pulmonary artery pressure, wedge pressure, and mitral valve gradient.

The reduction of TLCo shown by our patients agrees with the findings of most other studies; ${ }^{15-19}$ but when simple correlations with haemodynamic data were sought in two previous studies ${ }^{1620}$ none were found. Some studies of mitral stenosis have suggested that the pulmonary capillary blood volume is high in the early stages of the disease, which leads to a rise in Tuco at this stage. ${ }^{116172021}$ Our patients showed a fall in TLco with increasing severity of valve disease and we did not observe any early rise. The reduction in TLCo may result in part from maldistribution of ventilation. Account is taken of this by expressing TLco per litre of ventilated lung (that is, as the $\mathrm{Kco}$ ), and this was on average less reduced than the total TLco (table 2). Nevertheless, the Kco did show significant correlations with wedge pressure and mitral gradient, indicating that maldistribution of ventilation was only a partial explanation for the reduced TLCo and, even in normally ventilated lung units, the rate of carbon monoxide uptake was inversely related to the severity of the mitral disease.

At a practical level in an individual patient with mitral valve disease clinicians are often faced with the question of how to distinguish between the functional consequences of primary respiratory disease and those of the cardiac disease. Patients with chronic airflow obstruction caused by cigarette smoking also show a raised residual volume and low $T_{L C O}$; but the present study suggests that as consequences of mitral valve disease per se (1) chronic cough and sputum production are infrequent; (2) although episodic wheezing is fairly common, the $\mathrm{FEV}_{1} / \mathrm{VC}$ ratio is usually normal; (3) the total lung capacity (measured by plethysmography) tends to be normal, whereas in primary airway disease it is usually increased.

The authors wish to thank Mr AH Kendrick for technical assistance and the consultant cardiologists of Freeman Hospital for permission to study their patients. The investigations were performed during the tenure by KMR of a regional research fellowship awarded by the Northern Regional Health Authority.

\section{References}

1 Palmer WH, Gee JBL, Mills FC, Bates DV. Disturbances of pulmonary function in mitral valve disease. Canad Med Ass J 1963;89:744-50.

2 Frank NR, Cugell DW, Gaensler EA, Ellis LB. Ventilatory studies in mitral stenosis: A comparison with findings in primary pulmonary disease. Am J Med 1953; 15:60-76.

3 Robertson JD, Reid DD. Standards for the basal metabolism of normal people in Britain. Lancet 1952;i:940-3.

4 Gorlin R, Gorlin SG. Hydraulic formula for calculation of the area of the stenotic mitral valve, other cardiac valves and central circulatory shunts. Am Heart J 1951;41:1-29.

5 DuBois AB, Botelho SY, Bedell GN, Marshall R, Comroe JH Jr. A rapid plethysmographic method for measuring thoracic gas volume.J Clin Invest 1956;35:322-6.

- Ogilvie CM, Forster RE, Blakemore WS, Morton JW. A standardised breath holding technique for clinical measurement of the diffusing capacity of the lung for carbon monoxide. J Clin Invest 1957;36:1-17.

, Cotes JE. Lung function. 4th ed. Oxford: Blackwell 1979.

8 Peabody FW, Wentworth JA. Clinical studies of the respiration. IV. The vital capacity of the lungs and its relation to dyspnoea. Arch Int Med 1917;20:443-67.

- Cosby RS, Stowell EC, Hartwig WR, Mayo M. Abnormal ventilatory patterns in mitral stenosis. Dis Chest 1956;29:633-40.

10 Friedman BL, Macias J De J, Yu PN. Pulmonary function studies in patients with mitral stenosis. Am Rev Tub 1959;79:265-72.

1 Woolf CR. The relationships between dyspnoea, pulmonary function and intracardiac pressures in adults with $\dot{\delta}$ left heart valve lesions. Dis Chest 1966;49:225-40.

12 Dogliotti GC, Angelino PF, Brusca A, Garbagni R, Gavosto F, Magri G, Minetto E. Pulmonary function in mitral valve disease: haemodynamic and ventilatory $\frac{D}{0}$ studies. Am J Cardiol 1959;3:28-39.

13 Garbagni R, Angelino PF, Brusca A, Minetto E. N Residual lung volume in mitral disease. Br Heart $J$ 1958;20:479-82.

14 Wood TE, McLeod P, Anthonisen NR, Macklem PT. N Mechanics of breathing in mitral stenosis. Am Rev Resp Dis 1971;104:52-60.

is Curti PC, Cohen G, Castleman B, Scannel JG, Friedlich $\stackrel{\circ}{C}$ AL, Myers GS. Respiratory and circulatory studies of $\mathbb{D}$ patients with mitral stenosis. Circulation? 1953;8:893-904.

16 Hamer J. The pulmonary capillary bed in mitral valve disease. Br Heart J 1965;27:319-32.

17 McCredie RM. The diffusing characteristics and pressure $\mathbb{\mathbb { D }}$ volume relationships of the pulmonary capillary bed in mitral valve disease. J Clin Invest 1964;43:2279-89. 
18 Reid JM, Stevenson JG. Pulmonary diffusing capacity in mitral valve disease. Br Heart J 1963;25:741-7.

19 Fowler NO, Cubberly R, Dorney E. Pulmonary blood distribution and oxygen diffusion in mitral stenosis. $\mathrm{Am}$ Heart J 1954;48:1-7.

20 Flatley FJ, Constantine H, McCredie RM, Yu PN. Pulmonary diffusing capacity and pulmonary capillary blood volume in normal subjects and in cardiac patients. $\mathrm{Am}$ Heart J 1962;64:159-68.

21 Bates DV, Varvis CJ, Donevan RE, Christie RV. Variations in the pulmonary capillary blood volume and membrane diffusion component in health and disease. J Clin Invest 1960;39:1401-8. 